Check for updates

London, UK

Cite this as: BMJ 2020;369:m2631 http://dx.doi.org/10.1136/bmi.m2631 Published: 30 June 2020

\section{Drug misuse rose $30 \%$ in past decade and covid-19 could worsen situation, UN report warns}

Adrian O'Dowd

The number of people using illegal drugs globally has risen by $30 \%$ over the past decade to 269 million while 35.6 million people have drug use disorders, according to the latest World Drug Report ${ }^{1}$ from the United Nations Office on Drugs and Crime (UNODC).

The report, published on 25 June, also warns that the covid-19 pandemic could worsen the situation because the resulting restrictions on borders and other areas are causing shortages of drugs locally, leading to increased prices and reduced purity.

UNODC's report gives a global overview of the supply and demand of opiates, cocaine, cannabis, amphetamine type stimulants, and new psychoactive substances, and their impact on health.

Cannabis was the most used substance worldwide in 2018, with an estimated 192 million people using it, the report said. It noted that while frequent use of cannabis had increased in all countries that had legalised it, it remained the main drug that brought people into contact with the criminal justice system.

Opioids, however, remained the most harmful drug. Over the past decade, the total number of deaths from opioid use disorders rose by $71 \%$ to more than 110000 in 2017.

An estimated 58 million people were using opioids in 2018, and they accounted for $66 \%$ of the estimated 167 ooo deaths related to drug use disorders in 2017.

Drug use increased far quicker among developing countries over the 2000-2018 period than in developed countries, with adolescents and young adults accounting for the largest share of those using drugs.

The report's authors warned about the potential impact on drug use of the covid-19 pandemic, which was raising prices and reducing the purity of drugs.

The pandemic could mean drug traffickers would find new routes and methods, and lead to opioid shortages, which, in turn, could result in people seeking out more readily available substances such as alcohol, benzodiazepines, or mixing with synthetic drugs.

Rising unemployment and reduced opportunities caused by the pandemic were also likely to disproportionately affect the poorest people, making them more vulnerable to drug misuse and also to drug trafficking and cultivation, they said.

UNODC executive director Ghada Waly said, "Vulnerable and marginalised groups, youth, women, and the poor pay the price for the world drug problem.

"The covid-19 crisis and economic downturn threaten to compound drug dangers further still, when our health and social systems have been brought to the brink and our societies are struggling to cope.

"We need all governments to show greater solidarity and provide support to tackle drug trafficking and offer evidence based services for drug use disorders and related diseases, so we can achieve the Sustainable Development Goals, promote justice, and leave no one behind.”

But UNODC was criticised by the International Drug Policy Consortium (IDPC)-a global network of more than 195 non-governmental organisations-which said the former had not acknowledged the failure of decades of drug policies based on prohibition and punishment.

Ann Fordham, IDPC's executive director, said, “Despite some welcome progress in broadening out the World Drug Report's narrative to include greater mention of marginalised communities, the UNODC's wilful omission of any analysis of the unmitigated human rights impacts of repressive drug control measures is indefensible.

"There is overwhelming evidence that drug laws have weaponised law enforcement against marginalised communities across the globe."

1 United Nations Office on Drugs and Crime. World drug report 2020. 25 June 2020. https://wdr.unodc.org/wdr2020/index.html. 